\title{
A LEITURA DE BOOK APPS NO CONTEXTO FAMILIAR: A INTERAÇÃO DE CRIANÇAS COM A OBRA MEU APLICATIVO DE \\ FOLCLORE
}

\author{
Roberta Gerling Moro ${ }^{1}$ \\ Edgar Roberto Kirchof ${ }^{2}$
}

\section{RESUMO}

O objetivo deste artigo é apresentar a análise dos dados coletados em uma pesquisa de campo em que foi realizada a leitura do book app Meu Aplicativo de Folclore, do poeta brasileiro Ricardo Azevedo, por crianças entre 3 e 10 anos de idade no contexto familiar. A pesquisa busca compreender como as crianças interagem com as estruturas de leitura previstas em aplicativos literários (book apps), aqui apresentados como: (1) recursos de tela; (2) recursos de transição; (3) recursos de interação. Os resultados sugerem que as crianças têm preferência por obras com maior nível de interatividade e imersão, provavelmente devido a suas experiências prévias com jogos eletrônicos e outros tipos de aplicativos.

Palavras-chave: Literatura digital infantil. Leitura. Aplicativo literário. Interatividade.

\section{READING BOOK APPS IN FAMILY CONTEXTS: AN ANALYSIS OF CHILDREN' INTERACTIONS WITH MEU APLICATIVO DE FOLCLORE}

\begin{abstract}
The main goal of this article is to present the analysis of the data collected in a field survey in which the app Мeu Aplicativo de Folclore by the Brazilian poet Ricardo Azevedo was read by children between 3 and 10 years old in their homes. The research aimed to understand how children interact with reading structures in book apps such as: (1) tableau features; (2) transition features; (3) interaction features. The findings point to the fact that children prefer digital features that allow for high levels of interactivity and immersion, which probably happens due to their prior experiences with digital games and with other kinds of apps.
\end{abstract}

Keywords: Digital literature for children. Reading. Book apps. Interactivity.

\footnotetext{
${ }^{1}$ Mestre em Educação (PPGEDU-ULBRA) e licenciada em Artes Visuais pela Universidade Luterana do Brasil (Ulbra), Canoas, RS, Brasil.

${ }^{2}$ Doutor em teoria da literatura e professor no Programa de Pós-Graduação em Educação e Estudos Culturais da Universidade Luterana do Brasil (Ulbra), Canoas, RS, Brasil.
} 


\section{INTRODUÇÃO}

Uma das primeiras reações do mercado editorial frente ao surgimento e à popularização das tecnologias digitais foi oferecer versões digitalizadas dos livros impressos para compra e venda, os assim chamados e-books, que podem ser lidos em um desktop, em um celular, em um tablet, mas também nos e-readers (livros eletrônicos) produzidos por empresas como a Kindle, entre outros. Esses livros geralmente são produzidos com programas como o PDF ou o EPUB e, embora sejam digitais, possuem poucos ou nenhum recurso de multimídia e de hipermídia.

Versões mais recentes de livros digitais incluem também os assim chamados book apps (também chamados de livros-aplicativos ou livros interativos). Ao passo que o e-book é um arquivo que pode ser replicado e enviado, entre outros, através de e-mail e das redes sociais, o livro interativo é um tipo de software de aplicação que precisa ser baixado de lojas como iTunes, Google Play ou do site de alguma editora independente. Juntamente com os traços tradicionais dos e-books, tais como texto e imagens mostrados de forma digital, ícones de navegação e telas iniciais, por exemplo, os livros interativos também permitem mover imagens e letras com o toque dos dedos, brincar com joguinhos (alguns dos quais podem se interativos), iniciar pequenas animações, ouvir músicas e efeitos sonoros que acompanham as narrativas. Eles também permitem ouvir a história ao invés de lê-la, pois estão equipados com dispositivos de leitura automática. Em poucos termos, os livros interativos estão dotados de recursos de hipermídia, multimídia e interatividade. Alguns exemplos que podemos citar aqui são os livros interativos $O$ rei do rio de ouro, uma adaptação realizada do conto de John Ruskin pela Story Max, Flicts, uma adaptação realizada da obra do cartunista brasileiro Ziraldo pela Mafuá, entre muitos outros.

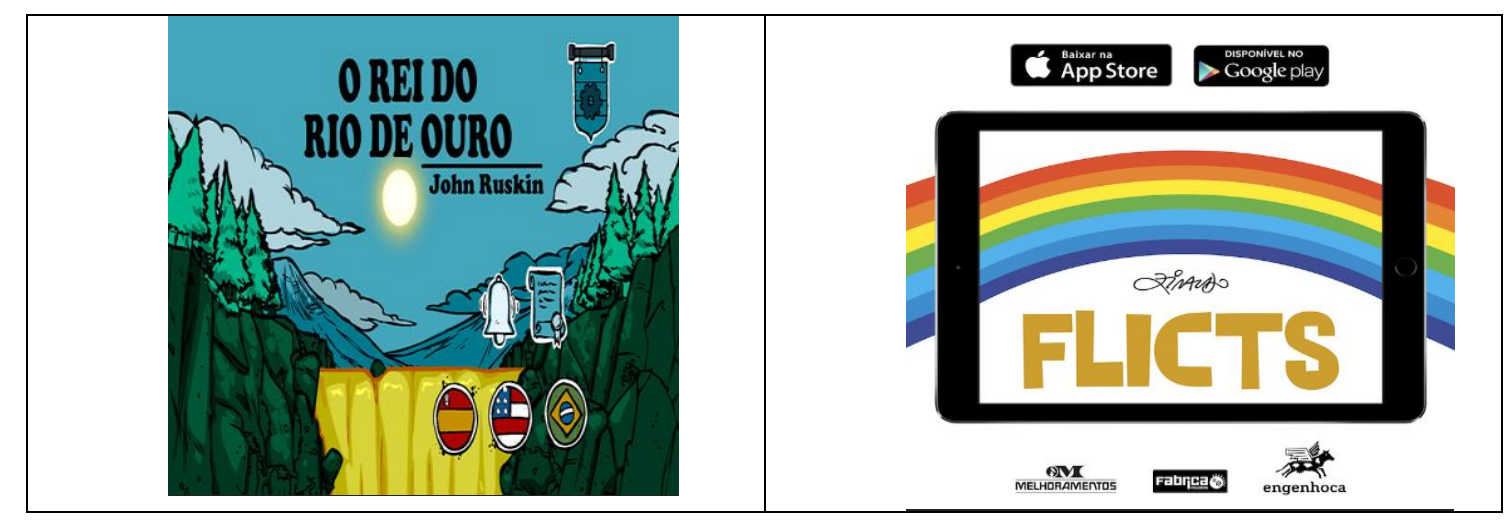

Figura 1. O Rei do Rio de Outro e Flicts (capas) 
Com intuito de compreender a estrutura dos book apps, Serafini, Kachorsky e Aguilera (2016) levam em consideração três tipos de recursos, a saber: a) recursos de tela; b) recursos de transição; c) recursos de interação. Os recursos de tela podem ser equiparados aos elementos que compõem a capa de um livro impresso. No caso dos aplicativos, os recursos de tela estão presentes numa tela específica ou no modo de abertura e de visualização do book app. Já os recursos de transição permitem que o leitor navegue ou transite entre as páginas, o que ocorre, no livro impresso, quando o leitor vira as páginas. Por fim, os recursos que mais diferenciam um book app de um livro impresso são os recursos de interação, responsáveis por permitir uma leitura multimídia, além de também proporcionarem a navegação para além da obra que está sendo lida, na medida em que podem remeter o leitor para conteúdos e plataformas externas ao próprio aplicativo. Como recursos de interação, ainda podem ser citadas as animações, os vídeos, as narrações automáticas, os hiperlinks e os assim chamados hot spots (áreas específicas na tela do dispositivo onde o leitor pode tocar, mover e pinçar para interagir com os sons, animações, ou até mesmo com os conteúdos adicionais durante a leitura).

Apesar de ainda serem recentes e não terem alcançado uma popularidade tão alta entre grandes públicos, já há um número expressivo de estudos sobre esse tipo de obra, os quais abordam desde questões mais formais envolvendo a produção e o design de book apps (Menegazzi, 2018) até questões mais voltadas para a sua qualidade estética e literária (cf. Teale \& Yokota; 2017; Correro \& Real, 2014; Serafi, Kachorsky, Aguilera, 2016), questões cognitivas e pedagógicas envolvidas na leitura (cf. Bus; Takacs; Kegel, 2015), práticas de mediação e estratégias de leitura (cf. Correro, Real, 2014; Frederico, 2016), entre várias outras. Pedagogicamente, um dos grandes desafios que essas novas formas do livro nos impõem é a necessidade de ler textos multimodais, os quais apresentam as informações usando não apenas a linguagem verbal, composta por palavras, frases, mas também imagens em movimento, animações, vídeos, canções, efeitos sonoros, cores, interatividade e jogabilidade.

Levando em conta esse contexto, o objetivo deste artigo é apresentar parte dos resultados de uma pesquisa sobre a leitura de book apps literários no contexto familiar, realizada com crianças de 3 a 10 anos de idade. $\mathrm{O}$ artigo apresenta um recorte feito a 
partir de uma pesquisa mais ampla desenvolvida como dissertação de mestrado ${ }^{3}$, cujo tema é a leitura da literatura digital infantil. Nesse sentido, para a realização da pesquisa, partiu-se do seguinte questionamento: "Como as crianças leem book apps em dispositivos móveis?". Para tanto, foi organizada e planejada uma pesquisa de campo para a observação da interação das crianças com as obras. $\mathrm{Na}$ dissertação, foram analisados os dados gerados a partir do trabalho com os seguintes livros digitais: Mini Zoo, Quem soltou o Pum?, Spot, Chomp, Flicts, Boum!, Meu Aplicativo de Folclore e Árvore dos Sonhos. Neste artigo, contudo, por uma questão de delimitação, serão apresentados apenas os dados relativos à leitura da obra Meu Aplicativo de Folclore.

Para atingir seu objetivo, este artigo está organizado em três partes principais: após esta breve introdução, a primeira parte explicita as questões relacionadas com a seleção das crianças como sujeitos da pesquisa e com a metodologia empregada para a coleta dos dados nas residências das famílias; na segunda parte, apresenta-se o aplicativo literário selecionado para este artigo, a saber, Meu Aplicativo de Folclore, do poeta brasileiro Ricardo Azevedo, com ênfase nos recursos propriamente digitais integrados à obra; na terceira parte, com base nos conceitos recursos de tela, de transição e de interação - postulados por Serafini, Kachorsky e Aguilera (2016) para definir a estrutura de aplicativos literários - são apresentadas as análises dos processos de leitura e interação realizados pelas crianças. Para finalizar, na última seção, apresentam-se algumas das principais conclusões alcançadas com o estudo.

\section{Questões metodológicas}

Para realizar a pesquisa de campo, em um primeiro momento, foi lançado um convite para famílias moradoras de um condomínio ${ }^{4}$ que tivessem crianças ${ }^{5}$ com idades entre 3 a 10 anos e que se interessassem em participar da pesquisa. Após as respectivas negociações com as famílias, foram selecionados, como sujeitos da pesquisa, as seguintes crianças: Gabriel, 3 anos, Elena, 4 anos, Isabella, 7 anos, Ana Paula, 8 anos e Rafael, 10 anos $^{6}$. Em um segundo momento, foram marcadas três entrevistas com os

\footnotetext{
${ }^{3}$ A pesquisa pode ser baixada no site https://www.elitforchildren.com/

${ }^{4}$ Localizado na cidade de Osório/RS.

${ }^{5}$ Como se trata de uma pesquisa que envolve crianças, foi necessário submeter o projeto de pesquisa ao Comitê de Ética da Universidade Luterana do Brasil, a fim de cumprir os requisitos éticos propostos para a pesquisa com seres humanos. O projeto foi elaborado e submetido no mês de junho de 2016, sendo aprovado em julho do mesmo ano. CAAE: 56844416.1.0000.5349

${ }^{6}$ Os nomes foram modificados, de modo a preservar o anonimato das crianças. Da mesma forma, as imagens das crianças utilizadas neste artigo foram submetidas a um processo de edição, tornando seus rostos irreconhecíveis.
} 
pais, para uma verificação das práticas de leitura da família e do uso de mídias digitais por parte das crianças, o que foi levado em conta quando foram definidas as obras que comporiam as atividades de leitura.

Tendo em vista que as famílias optaram pela realização dos encontros em suas próprias residências, foi necessário organizar um planejamento que pudesse contemplar as crianças de cada família. Por essa razão, as sessões de leitura foram divididas por grupos de leitores, sendo que cada grupo está relacionado a uma família, os quais são: Grupo 1, apenas Gabriel, 3 anos; Grupo 2, composto pelas meninas Elena, 4 anos e Isabella, 7 anos e Grupo 3, pelos irmãos Ana Paula, 8 anos e Rafael, 10 anos. Posteriormente, as obras foram distribuídas de acordo com os grupos de leitores, idades, nível de letramento literário e digital.

Após a seleção das obras, foi construído um planejamento para os encontros com as crianças. Cada atividade de leitura foi planejada levando em conta três fases, inspiradas nas estratégias de leitura sugeridas por Solé (2008) e nos roteiros de leitura propostos por Saraiva, Mello e Varella (2001), assim definidas: $1^{\text {a }}$ Fase: conversa informal com as crianças sobre a utilização do dispositivo e sobre questões contextuais relativas à obra selecionada para leitura; $2^{\mathrm{a}}$ Fase: interação individual ou em dupla das crianças com o aplicativo literário selecionado, com ênfase na exploração dos seus recursos literários e digitais; $3^{\mathrm{a}}$ Fase: atividade de transferência (desenho/pintura), realizada no próprio dispositivo a partir da utilização do software ArtRage, com ênfase na produção de imagens digitais por parte das crianças. As atividades realizadas a partir dessas fases foram gravadas e posteriormente transcritas para serem utilizadas nas análises, assim como também foram armazenadas as produções digitais realizadas pelas crianças na terceira fase. As atividades ocorreram no período de setembro a outubro de 2016, com uma média de 5 encontros mensais.

\section{Meu Aplicativo de Folclore}

O aplicativo selecionado, criado pelo poeta brasileiro Ricardo Azevedo e publicado pela Editora Ática, foi vencedor do prêmio Jabuti 2015 e está disponível para compra em lojas virtuais como a App Store, podendo ser baixado em dispositivos com sistemas Android e iOS. Os textos e as ilustrações que compõem o book app foram adaptados a partir das obras Meu livro de folclore (1996), Armazém do folclore (2000), No meio da noite escura tem uma pé de maravilha! (2001), Contos de bichos do mato 
(2004) e Contos e lendas de um vale encantado ( 2010), todas do próprio Ricardo Azevedo.

De um modo geral, o aplicativo é composto por textos folclóricos e ilustrações que fazem referência à cultura popular brasileira e nordestina, como contos, parlendas, trava-línguas, ditados, adivinhas, bestiário e brincadeiras. Na página inicial, há ícones (hiperlinks) que direcionam o leitor aos textos literários e a algumas brincadeiras. Ao tocar sobre determinado ícone, outra página se abre. Na parte inferior da página, há ainda mais cinco ícones: Home (página inicial), Brincadeiras (rádio trava-línguas, ditados e colorir), Ricardo Azevedo (informações sobre a vida e obra do autor), Ajuda e Créditos da obra. Na parte superior do aplicativo, podem ser explorados outros ícones sem a necessidade de retornar, assim, à página inicial.

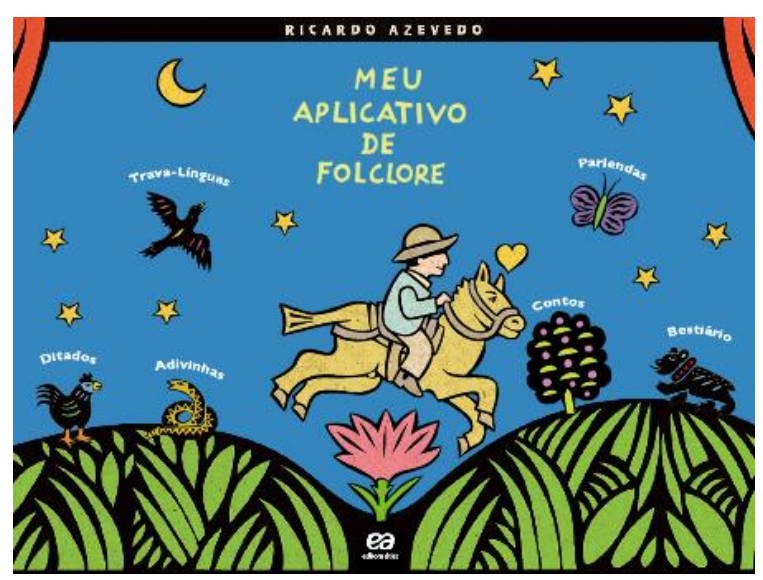

Figura 2. Meu Aplicativo de Folclore (capa)

Ao analisar a capa do book app, é possível perceber que as imagens se assemelham à técnica de xilogravura utilizada na Literatura de Cordel. Os contornos das formas, bem como o preenchimento dos desenhos, aproximam-se esteticamente das incisões produzidas sobre a madeira no momento da produção de uma xilogravura. $\mathrm{O}$ processo de produção da Literatura de Cordel consiste na impressão das gravuras sobre pequenos folhetos que, depois, são distribuídos em várias cidades por vendedores ambulantes, principalmente no território nordestino. A figura central do aplicativo, um homem (vaqueiro) montado sobre um cavalo/mula, possui semelhança com as capas onde eram representados os vaqueiros em sua labuta. A música que acompanha os textos foi composta por Yuri Prado e faz referência ao repertório de canções populares do Nordeste.

Muitos dos poemas adaptados pelo autor no aplicativo já são bastante conhecidos entre as crianças brasileiras, mas a versão digital está dotada de alguns 
recursos multimídia que proporcionam uma leitura diferenciada desses textos. O ícone representado pelo desenho de uma borboleta, por exemplo, apresenta quatro parlendas, onde o leitor pode acompanhar a leitura pelo destaque dado às palavras, em verde, e ouvir a narração, de forma cantada (a leitura de cada parlenda é repetida três vezes). Outro recurso multimídia associado às parlendas são as animações produzidas em cada estrofe. Além de ouvir os poemas e canções, o leitor também pode gravá-las com a sua própria voz. Essa opção pode ser encontrada também nos trava-línguas: é possível lê-los e, depois, gravá-los através do "rádio trava-línguas".

Nas adivinhas, ao tocar sobre cada figura, surge automaticamente um texto acompanhado de uma narração que propõe uma questão ao leitor. Enquanto o leitor pensa em sua resposta, o som do tique-taque do relógio lembra que o tempo está passando. Entretanto, se o leitor não souber a resposta, bastará tocar sobre a pergunta (retângulo verde), e a resposta aparecerá automaticamente.

Já os ditados são adaptados na forma de quebra-cabeças de apenas duas peças cada. É necessário que o leitor encaixe as duas peças (deslizando o dedo fixo sobre uma das peças em direção à outra) corretamente para que cada ditado faça sentido. Depois que as duas peças são encaixadas na forma correta, uma caixa surge com um texto explicando o significado do ditado.

O aplicativo contém apenas dois contos, os quais não são interativos e tampouco estão ampliados com recurso de animação: Dois cegos briguentos (versão de uma anedota popular) e $O$ filho da filha do bicho-preguiça. Ao lado do texto, há apenas uma ilustração, e o leitor pode acompanhar a sua leitura pela música e pela narração automática, sendo necessário, para tanto, apenas rolar o texto através da barra no canto direito.

O bestiário conta com recursos interativos. Tocando sobre as figuras mitológicas, um pequeno texto descritivo sobre cada criatura aparecerá em outra página. Abaixo do desenho, há também a opção de "colorir" o personagem. Se o leitor optar pela atividade de colorir, o desenho escolhido aparecerá novamente em outra página, juntamente com uma paleta de cores. Para colorir a imagem, basta tocar sobre a cor desejada e deslizar sobre a parte da imagem a ser colorida (como uma "pintura a dedo"). O leitor ainda tem a opção de salvar sua pintura ou de apagar tudo e começar novamente.

\section{Como as crianças interagiram com o aplicativo?}


Para responder ao questionamento "Como as crianças interagiram com o aplicativo?", é necessário relembrar, em um primeiro momento, que as principais estruturas presentes em aplicativos podem ser resumidas a recursos de tela, de transição e de interação, segundo Serafini, Kachorsky e Aguilera (2016). No caso de Meu Aplicativo de Folclore, na tela inicial, os elementos que compõem os recursos de tela são o nome do autor, Ricardo Azevedo, em letras brancas e em fundo preto; logo abaixo, o título, em amarelo (tanto o texto do autor quanto o título são estáticos); no centro, uma animação de um homem montado sobre um cavalo, que dá destaque à capa; e seis hiperlinks estáticos representados por imagens que permitem, ao leitor, entrar no texto do aplicativo: trava-línguas, ditados, adivinhas, parlendas, contos e bestiário. Além desses recursos visuais, há ainda uma música de fundo, fazendo referência a canções nordestinas populares, que acompanham o texto da capa.

De um modo geral, os ícones da capa deixaram as crianças desorientadas, pois elas não sabiam bem como deveriam interagir ou por onde começar. Provavelmente isso ocorreu pelo fato de a tela conter muita informação e ser pouco apelativa, no que diz respeito aos recursos de animação. Gabriel foi o único leitor a relatar que faltavam mais elementos interativos e que os animais da capa, ou seja, os ícones, poderiam conter recursos de animação. Dessa maneira, os recursos de tela desse aplicativo pouco atraíram a atenção das crianças, que esperavam encontrar mais elementos multimidiáticos.

No caso dos recursos de transição, a forma como o leitor transita entre as páginas/telas do aplicativo ocorre somente através dos hiperlinks dispostos na capa e nas páginas/tela da narrativa. Aqueles ícones que compõem a capa direcionam o leitor aos textos literários e às brincadeiras. Ao tocar sobre determinado ícone, como o bestiário, por exemplo, abre-se outra página. Há, ainda, outros cinco ícones disponibilizados na parte inferior de cada página/tela: Home, (redireciona o leitor à tela inicial/capa); Brincadeiras (abre-se uma outra janela com atividades, como travalínguas, ditados e colorir); Ricardo Azevedo (permite ao leitor se informar a respeito da vida e obra do autor); Ajuda, representado na figura de um ponto de interrogação (auxilia o leitor sobre questões relativas às funções do aplicativo, como o modo de gravação dos trava-línguas, por exemplo) e Créditos (informações sobre a obra e produtores envolvidos).

Por outro lado, na parte superior de cada página/tela, há os mesmos ícones dispostos na capa do aplicativo. Se o leitor não quiser retornar à tela inicial, é possível 
transitar entre as páginas/telas através destes ícones. Além disso, nos contos, travalínguas e parlendas, é possível transitar entre os textos através de setas na parte inferior da página/tela, o que permite, ao leitor, retornar a determinado texto ou passar para o seguinte. Isso pode ser visualizado na imagem a seguir, que ilustra o que foi explicitado anteriormente.

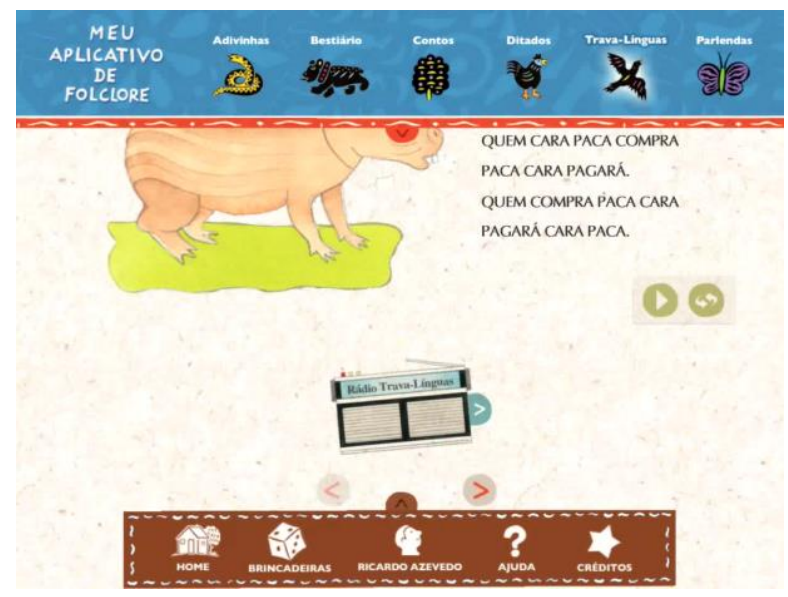

Figura 3 - Recursos de transição

No que diz respeito aos recursos de transição, as crianças entraram no texto do aplicativo através de um dos ícones da capa. Além disso, não utilizaram, como recursos de transição, os ícones dispostos na parte superior das páginas/telas, tampouco seguiram a ordem de disposição dos ícones: selecionavam primeiro aqueles que poderiam ser mais interessantes.

Gabriel, por outro lado, não se interessou pelos recursos de transição, tendo sido necessário interferir em sua leitura para que mudasse de tela. Dos vários momentos em que buscou-se direcionar a atenção do menino para o book app, houve somente um em que se percebeu que algum ícone - no caso, um ícone representado por uma cobra -, foi capaz de cativar o menino. Entretanto, isso ocorreu durante um curto espaço de tempo, já que, logo depois, ele saiu do aplicativo espontaneamente.

Embora a mediação também tenha sido necessária na passagem entre as páginas/telas durante a interação de Elena e Isabella, o fato de transitarem através de ícones na narrativa não desmotivou as meninas. Pelo contrário, conforme novas páginas/telas surgiam, elas demonstraram entusiasmo e continuaram interagindo com o aplicativo até o final.

Já Ana Paula e Rafael, no decorrer da leitura, realizada individualmente, souberam negociar com os ícones para passar de uma página/tela para outra. Contudo, 
não utilizaram os recursos de transição disponíveis em cada tela; sempre que desejavam passar para outro hiperlink, voltavam à tela inicial (capa) e selecionavam um ícone específico.

Os recursos de interação são muito simples, mas diferentes entre si, podendo ser encontrados ao tocar sobre cada um dos ícones, como adivinhas, bestiário, ditados e trava-línguas. Nos ditados, por exemplo, o leitor precisa montar duas peças, como em um quebra-cabeça, para realizar a leitura do texto. Para encaixar as peças, é preciso arrastar o dedo sobre uma peça até a outra, mas as peças precisam ser encaixadas de forma correta para que o leitor tenha acesso à explicação do ditado.

$\mathrm{Na}$ imagem a seguir, ao arrastar a peça "não entra mosca" na direção de sua peça complementar, "em boca fechada", completa-se o ditado "Em boca fechada, não entra mosca". Depois de encaixadas as peças, surge uma janela que explica o significado deste ditado.
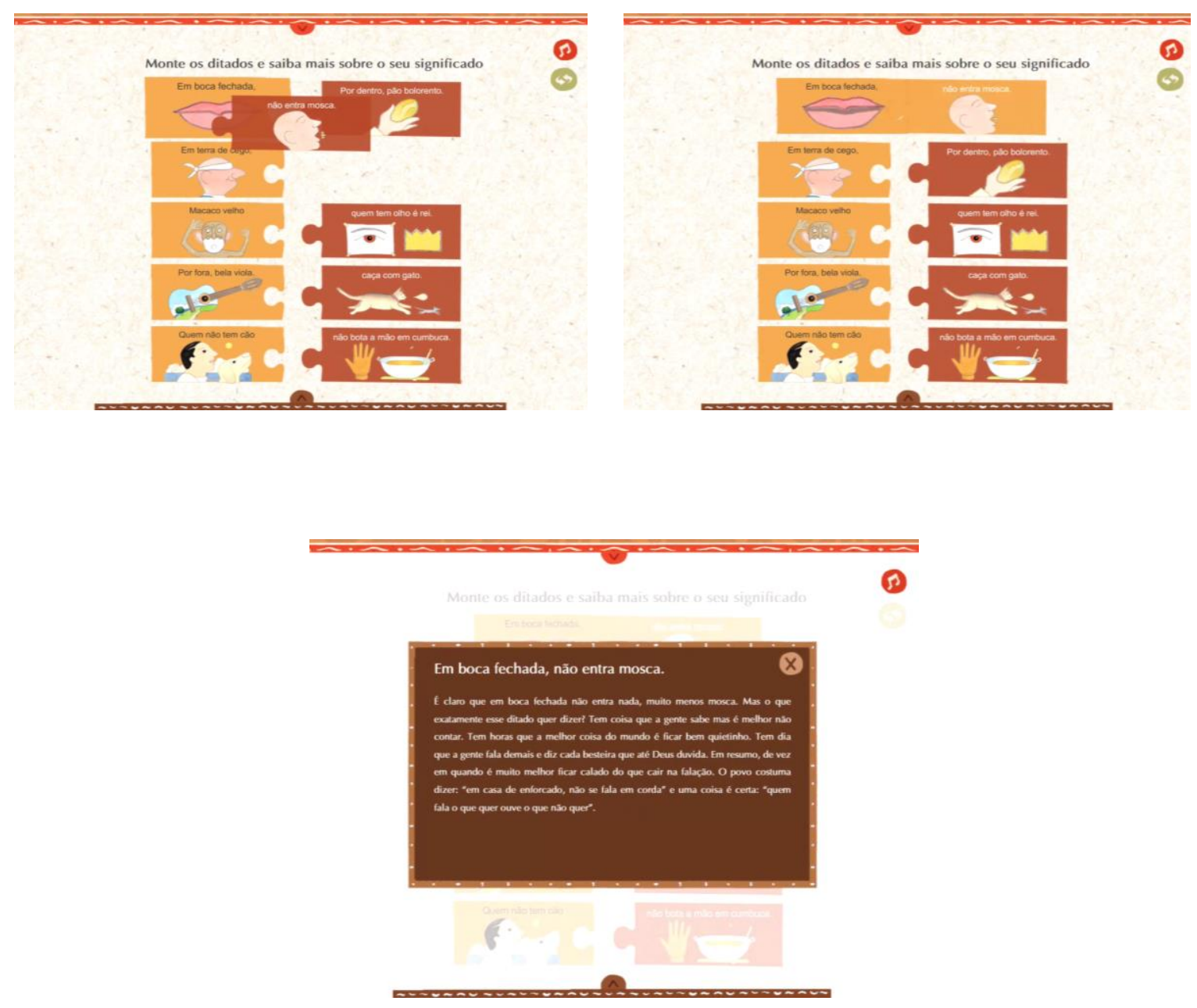

Figura 4. Sequência de imagens: ditado 
Os recursos de interação do bestiário também podem ser destacados. Ao tocar sobre uma das figuras mitológicas, uma nova página/tela surge com uma descrição da criatura. Nesta página/tela, o leitor pode optar por colorir o personagem, ao tocar sobre o ícone representado por um pincel. Logo, uma nova página/tela surge com o desenho escolhido pelo leitor, juntamente com uma paleta de cores. Há somente dez opções de cores, e é possível salvar a pintura no dispositivo ou apagá-la totalmente. Assim, para colorir o desenho, basta tocar sobre a cor desejada e deslizar sobre a parte da imagem a ser colorida. Além das figuras mitológicas, também é possível pintar os desenhos dos contos. É o caso das capturas de tela abaixo, que permitem visualizar o desenho do conto "O Filho da Filha do Bicho-Preguiça".
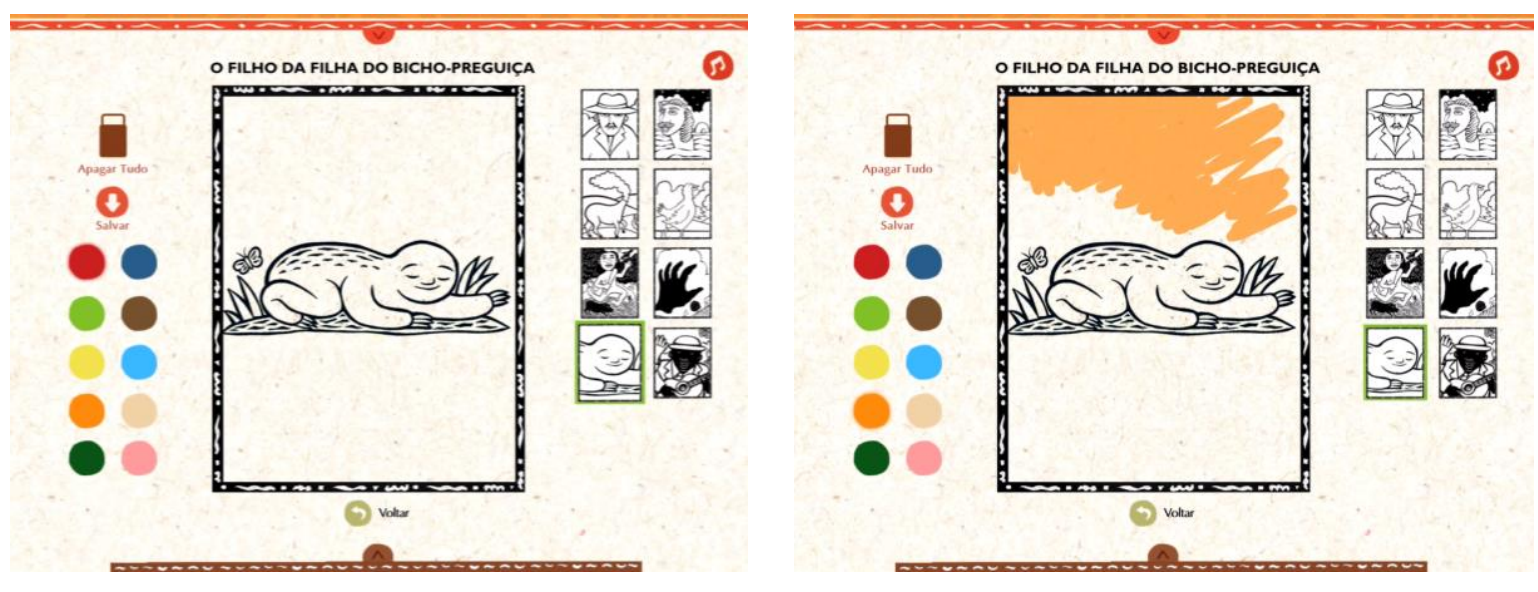

Uma vez que Gabriel não demonstrou muito interesse pelo aplicativo, foram poucos os momentos em que reagiu aos recursos de interação. Destacam-se dois deles: as adivinhas e o bestiário. Primeiro, nas adivinhas, o menino ficou atraído apenas pela possibilidade de tocar sobre as figuras e, desse modo, desencadear a leitura automática do aplicativo, algo que lhe proporcionou divertimento. Segundo, em sua interação com o bestiário, foi $\mathrm{o}$ que suas atitudes Figura 5. Atividade de pintura do aplicativo único momento em espontâneas, motivadas pela possibilidade de pintar o personagem no aplicativo. Ainda assim, permaneceu durante pouco tempo pintando o personagem escolhido, logo questionando se não tinha outra opção com a qual pudesse interagir. Em outras palavras, 
apesar do interesse evidente pelo recurso, Gabriel ficou insatisfeito com o aplicativo pelo fato de haver, em sua opinião, poucos recursos de multimídia.

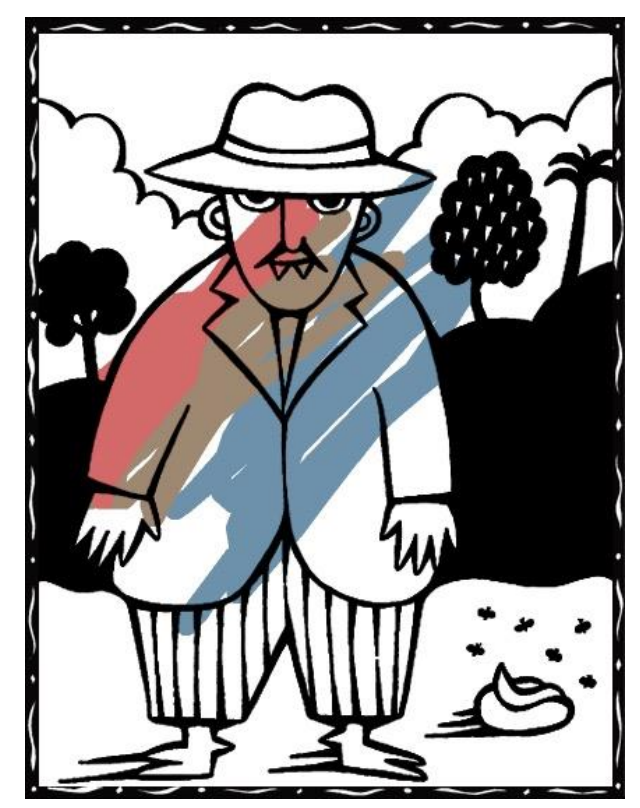

Figura 6. Personagem selecionado e colorido por uma criança no aplicativo

Visto que os demais grupos de leitores exploraram a maioria dos recursos de interação e atividades disponíveis no aplicativo, foi necessário organizar as análises por categorias, a saber, ditados, adivinhas, trava-línguas, bestiário, parlendas e contos. De um modo geral, as crianças ficaram interessadas em explorar os ditados, arrastando as peças de uma parte para a outra pela tela do dispositivo. Apesar de atraídas pelo recurso, conforme prosseguiam na leitura, aumentava o nível de complexidade dos ditados. Tanto Elena e Isabella quanto Ana Paula e Rafael souberam encaixar as peças nos locais corretos. Por outro lado, a leitura do significado de cada ditado só foi solicitada pelas irmãs Elena e Isabella, sendo que foi realizada a leitura em voz alta para elas. Ana Paula, por sua vez, pareceu se divertir com o ditado "Quem tem burro e anda a pé, ainda mais burro é”, mesmo não realizando a leitura do mesmo, conforme imagem abaixo. Por outro lado, Devido ao grau de complexidade dos textos de alguns ditados, foi necessário 
auxiliar Rafael, pois o menino queria encaixar as peças nos locais corretos e conhecer mais a fundo os ditados.

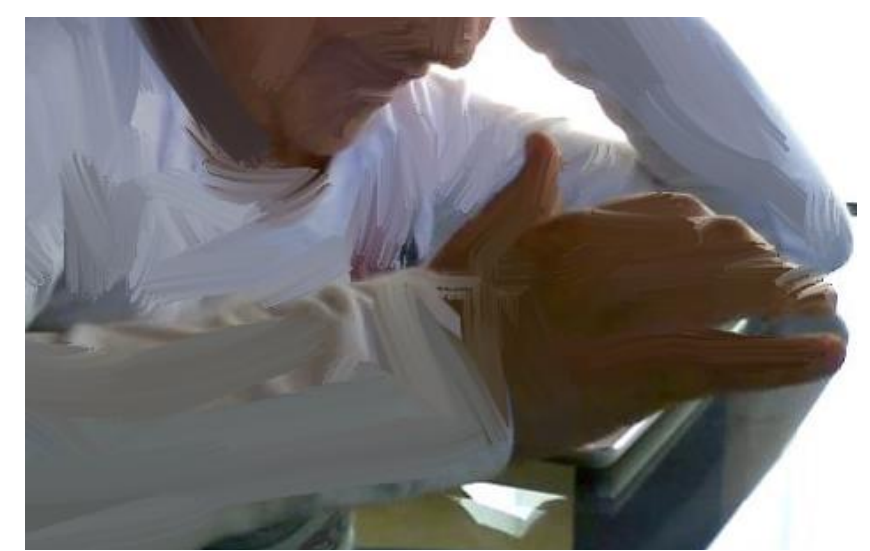

Figura 7. Ana Paula interagindo com o aplicativo

As crianças também ficaram muito atraídas pelas adivinhas, tentando descobrir por conta própria as suas respostas. Talvez isso tenha ocorrido por causa da presença de outros recursos, como o efeito sonoro do tique-taque do relógio e a própria narração automática. Isabella, por exemplo, quando não compreendia determinada resposta, voltava e ouvia a pergunta novamente. Como Elena ainda não era alfabetizada na época em que realizei a pesquisa, a menina acompanhava a irmã. O recurso de narração facilitou a sua compreensão da obra, permitindo que ouvisse com muita atenção cada adivinha. Já Ana Paula e Rafael falavam em voz alta o que talvez poderia ser a resposta antes de tocarem sobre o dispositivo.

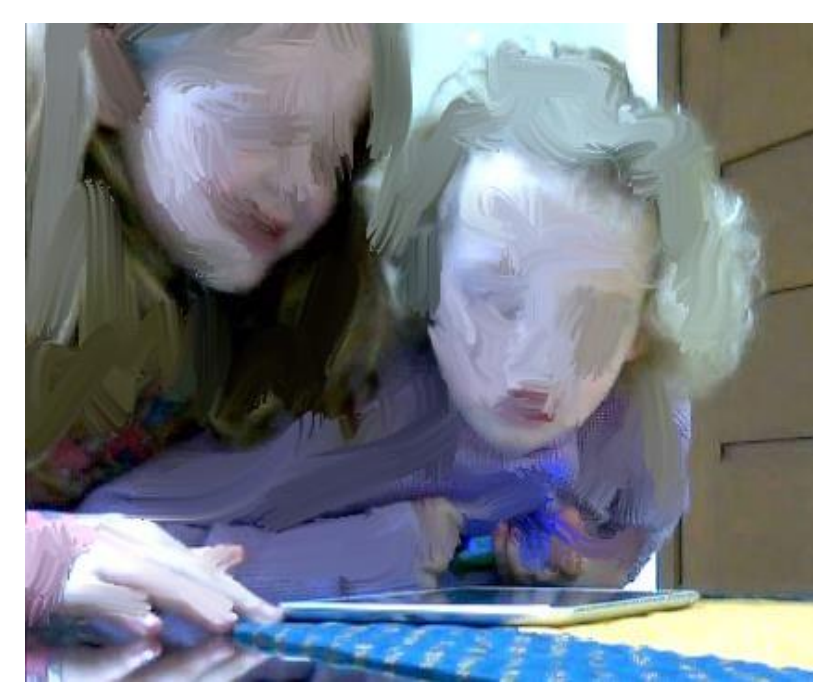

Figura 8. Elena e Isabella interagindo com as adivinhas 
Enquanto as meninas Elena e Isabella apenas ouviram os trava-línguas, Ana Paula tentava repetir em voz alta cada um deles. Rafael também aceitou o desafio, repetindo as frases, mas, por outro lado, quis explorar o recurso de gravação presente na página/tela dos trava-línguas. Entretanto, não foi possível realizar a gravação, pois o recurso não funcionou no dispositivo. Juntamente com o menino, tentou-se verificar se o procedimento era o correto. Mesmo assim, não funcionou, e o som do próprio aplicativo também foi desativado, só respondendo novamente após retornar à página inicial (capa). Apesar do obstáculo encontrado naquele momento, o menino não se desmotivou e continuou ouvindo os trava-línguas. Pode-se inferir que o recurso sonoro, em especial, a forma como os trava-línguas é apresentada no aplicativo - não como uma mera narração, mas como versos cantados - interessou e entusiasmou as crianças.

As crianças também se sentiram estimuladas pelas histórias e criaturas mitológicas apresentadas no bestiário. Isabella e Elena, por exemplo, selecionaram duas figuras mitológicas para a atividade de pintura: a Mula sem cabeça e Boiuna, solicitando a leitura das histórias das figuras selecionadas. Nas imagens que seguem, é possível observar a atividade de colorir as imagens, realizadas pelas crianças no aplicativo. Por outro lado, Ana Paula e Rafael não quiseram realizar esse atividade, mas se interessaram por ler todas as histórias do bestiário.
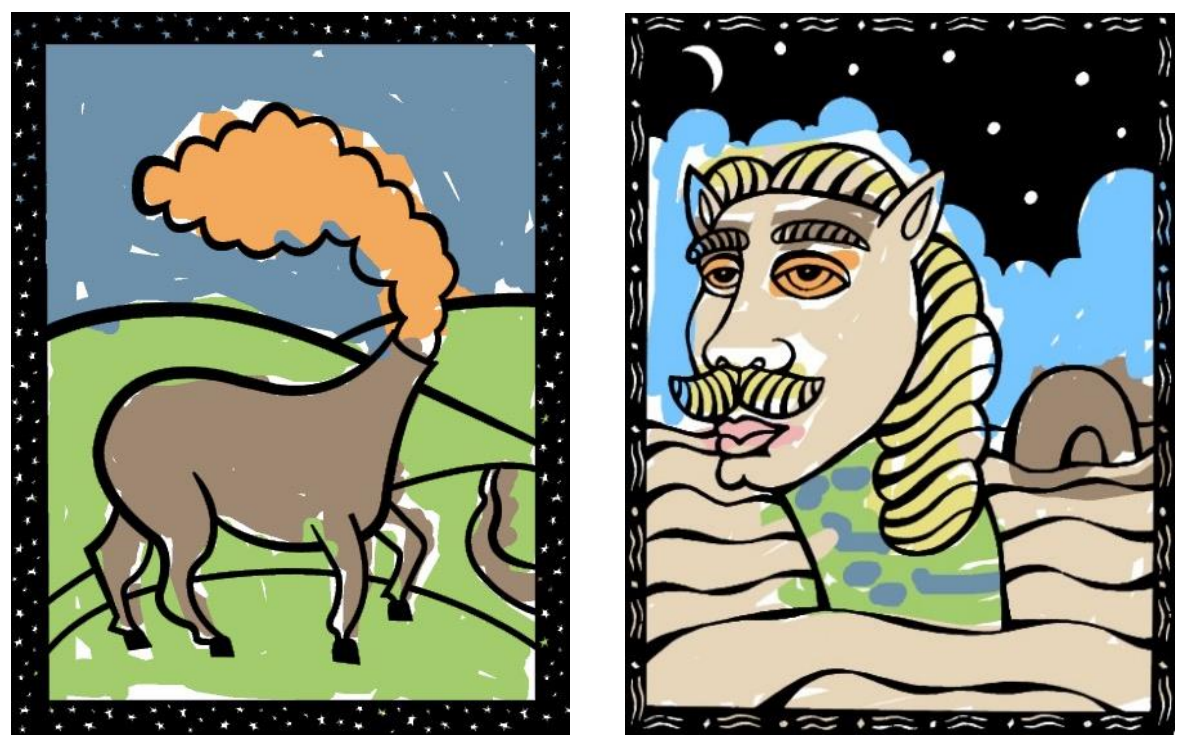

Figuras 9 e 10. Imagens coloridas pelas crianças 
No caso das parlendas, houve reações diferentes. Elena e Isabella estabeleceram um vínculo com esta parte do aplicativo, pois, conforme Elena relatou durante a leitura, já tinham conhecimento das parlendas através das versões impressas: "Tem no nosso livrinho" (fala de Elena). O entusiasmo de Isabella com essa atividade ficou evidente, pois, embora tenha demonstrado timidez ao longo dos encontros anteriores, leu em voz alta as parlendas juntamente com as narrações automáticas do aplicativo. A julgar por suas reações, é possível afirmar que o texto das parlendas foi o principal elemento do aplicativo que despertou interesse e deleite pela leitura, e não os recursos de animação e e efeitos sonoros.

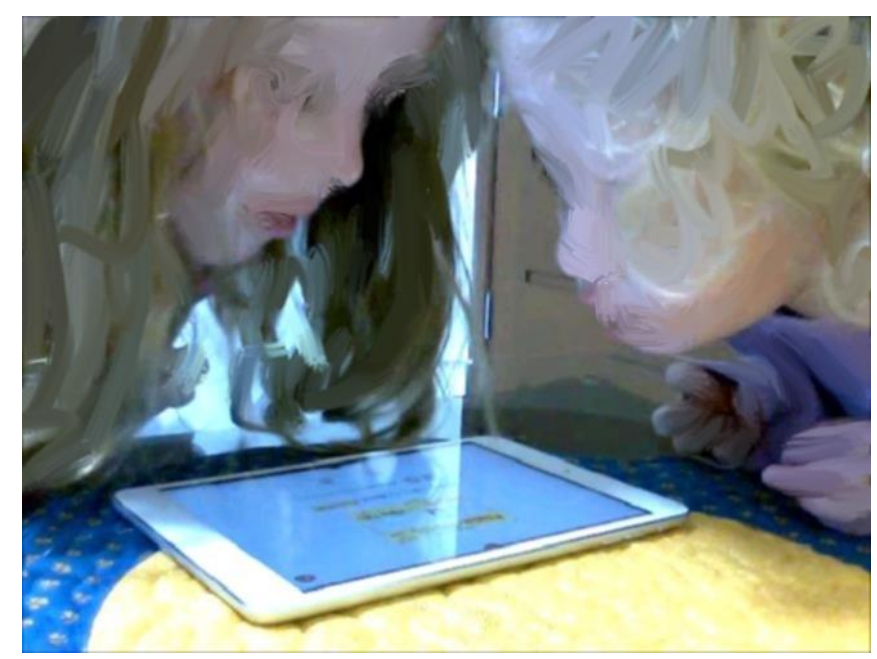

Figura 11. Meninas atentas às parlendas

Apesar do interesse de Ana Paula e Rafael, eles ouviram somente uma vez cada parlenda, passando rapidamente de um texto para outro. Destaca-se que o recurso sonoro, evidenciado pelos recursos de narração automática, foi o que mais divertiu as crianças nesse caso.

O recurso de narração dos contos aproximou as crianças do aplicativo, principalmente Elena, ainda não alfabetizada, e Isabella, que acompanhava a narração pelo texto verbal na tela do aplicativo. O conto que mais chamou a atenção das meninas foi "O Filho da Filha do Bicho-Preguiça", principalmente devido às entonações realizadas pela narração automática. 
Enquanto as meninas realizaram a leitura dos dois contos disponíveis no aplicativo, Ana Paula pouco se interessou, lendo apenas o primeiro, "Dois cegos briguentos". Rafael, por outro lado, não percebeu que o recurso de narração poderia ser ativado, realizando a leitura em voz alta, rindo e comentando em alguns momentos. Somente ao final da leitura dos dois contos, o menino resolveu explorar o botão que permitia ativar o recurso, lamentando, por fim, hão havê-lo percebido antes.

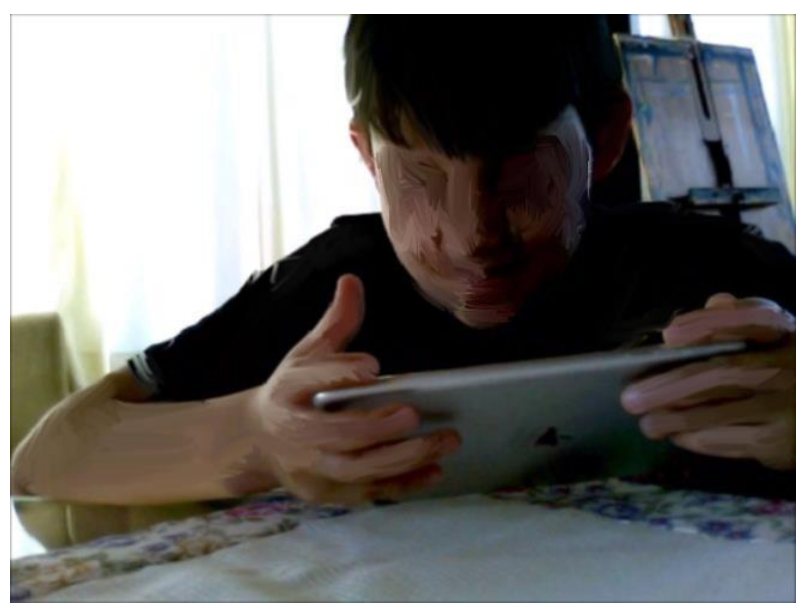

Figura 12. Rafael lendo os contos

\section{Conclusões}

Levando em consideração que a leitura do aplicativo pelas crianças foi realizada de forma autônoma, foi possível observar como elas interagiram com o aplicativo quando há pouca ou nenhuma interferência por parte de um mediador adulto. Nesse sentido, três reações principais foram verificadas: (1) o zappeamento e o acesso a outros aplicativos e jogos; (2) insegurança para explorar os recursos do aplicativo, tais como os ícones dispostos na tela inicial; (3) engajamento espontâneo, verificado principalmente durante a leitura das parlendas pelo grupo 2.

Uma das reações iniciais das crianças quando foi disponibilizado o aplicativo foi zappear, por vezes, procurando por “jogos digitais”. Gabriel, por exemplo, que já estava mais familiarizado com diferentes modalidades de mídias e jogos digitais, tentou acessar outros aplicativos presentes no dispositivo, como a Netflix ou aplicativos de jogos. No caso do menino, visto que a obra Meu Aplicativo de Folclore possui baixo nível de interatividade, sua reação foi a de procurar por outro aplicativo no aparelho, preferindo aqueles que oportunizavam maior interatividade e entretenimento.

A segunda reação observada durante as sessões de leitura foi uma certa insegurança inicial no manuseio do aparelho e na interação com o aplicativo. Isso 
ocorreu, principalmente, com Elena e Isabella, que, em certos momentos, permaneciam imóveis e não colaboravam com as estratégias de transição entre as páginas, manifestando poucas reações diante das possibilidades interativas.

Embora tenha sido possível verificar, de modo geral, relativamente pouco entusiasmo das crianças pelo aplicativo, pode-se afirmar, por outro lado, que houve um engajamento espontâneo, principalmente durante a leitura dos ditados, das adivinhas, das parlendas e da atividade de pintura. O grupo 3, por exemplo, ficou engajado com a leitura dos contos, que poderiam ser lidos ou ouvidos através da narração automática. Dessa forma, tanto a insegurança no manuseio do aplicativo quanto o zappeamento podem ter ocorrido, simplesmente, porque o próprio aplicativo não demanda, do leitor, uma cooperação muito interativa durante a leitura, o que eles de certa forma esperam por já estarem acostumados com jogos eletrônicos e outros aplicativos voltados para o entretenimento.

\section{REFERÊNCIAS}

BUS, Adriana G.; TAKACS, Zsofia K; KEGEL, Cornelia A.T. Affordances and limitations of electronic storybooks for young children's emergent literacy, Developmental Review, n. 35, 2015, p. 79-97, disponível em: <https://doi.org/10.1016/j.dr.2014.12.004>.

CORRERO, Cristina, REAL, Neus. Panorámica de la literatura digital para la educación infantil, Textura Canoas, n.32 p.224-244 set./dez. 2014. Disponível em: <http://www.periodicos.ulbra.br/index.php/txra/article/view/1255/945>.

FREDERICO, Aline. O futuro do leitor ou o leitor do futuro: o livro infantil interativo e os letramentos múltiplos. Cadernos de Letras da UFF Dossiê: A crise da leitura e a formação do leitor, $n^{\circ}$ 52, p. 101-120, 2016, Disponível em: <http://www.cadernosdeletras.uff.br/index.php/cadernosdeletras/article/view/195/120>.

MENEGAZZI, Douglas Luiz. O Design de interfaces de livros infantis apps: uma revisão das características e recomendações. Textura Canoas, n. 20, v. 43, p. 215-238 mai./ago., 2018. Disponível em:

<http://www.periodicos.ulbra.br/index.php/txra/article/view/3590/2940>.

SARAIVA, Juracy Assmann; MELLO, Ana Maria Lisboa de; VARELLA, Noely Klein. Pressupostos teóricos e metodológicos da articulação entre literatura e alfabetização. In: SARAIVA, Juracy Assmann (org). Literatura e alfabetização: do plano do choro ao plano da ação. Porto Alegre: Artmed Editora, 2001. p. 81-87. 
SERAFINI, Frank; KACHORSKY, Danielle; AGUILERA, Earl. Picture Books in the Digital Age. The Reading Teacher, v. 69, n. 5, p. 509-512, mar./abr. 2016.

SOLÉ, Isabel. Estratégias de leitura. 6.ed. Porto Alegre: Artmed, 2008.

\section{APLICATIVO ANALISADO}

AZEVEDO, Ricardo. Meu Aplicativo de Folclore. Editora Ática, 2015. Disponível para iOS e Android. 